\title{
O ACOLHIMENTO REALIZADO PELA EQUIPE DO CAPS AD DE FEIRA DE SANTANA: A PERCEPÇÃO DOS USUÁRIOS
}

\author{
Jaciele de Souza dos Santos ${ }^{1}$; Carina Pimentel Souza Batista ${ }^{2}$; Sinara Lima de Souza ${ }^{3}$ e \\ Camila Cerqueira Rios ${ }^{4}$ \\ 1. Bolsista PIBIC/CNPq, Graduando em Enfermagem, Universidade Estadual de Feira de Santana, e-mail: \\ jacisdossantos@gmail.com \\ 2. Orientador, Departamento de Saúde, Universidade Estadual de Feira de Santana, e-mail: \\ carinapimentel@hotmail.com \\ 3. Participante do projeto Percepção do acolhimento pelos usuários de um CAPS ad do interior da Bahia, \\ Departamento de Saúde, Universidade Estadual de Feira de Santana, e-mail: \\ sinarals@uefs.br \\ 4. Participante do projeto Percepção do acolhimento pelos usuários de um CAPS ad do interior da Bahia, \\ Departamento de Saúde, Universidade Estadual de Feira de Santana, e-mail: \\ mila.c.r@hotmmail.com
}

PALAVRAS-CHAVE: Saúde Mental; Acolhimento; Usuários.

\section{INTRODUÇÃO}

O acolhimento é uma tecnologia leve do processo mediador do trabalho em saúde e uma das diretrizes da Política Nacional de Humanização que possibilita a abertura para recepção de demandas dos usuários, visando o encontro entre o sujeito a ser cuidado e o trabalhador (BRASIL, 2006; MERHY, 1997).

O Centro de Atenção Psicossocial Álcool e outras Drogas (CAPS ad) destina-se a pessoas com sofrimento psíquico decorrente do uso, abuso ou dependência de álcool e outras drogas, contendo ações e estratégias direcionadas a redução dos fatores de risco, 0 fortalecimento de fatores de proteção além da redução de danos (BRASIL, 2004).

Silveira (2011) aborda que o estigma social poderia ser definido como uma marca ou um sinal que designaria ao seu portador um status "deteriorado" e, chegando ao ponto de incapacitar o indivíduo para a aceitação social. É preciso inserir discursões e assuntos sobre o uso dependente de álcool e outras drogas e sobre o CAPS ad, já que muitos indivíduos ainda o ver como um lugar para "loucos", gerando o preconceito social e a não procura dos usuários.

Os relatos de pacientes e a curiosidade aguçada de estender meu olhar, enquanto estudante de enfermagem, para as pessoas que buscam atendimento no CAPS ad, por inúmeras situações, me motivaram a estudar esta temática, na perspectiva do acolhimento, em virtude destes indivíduos serem associados à periculosidade e criminalidade.

Assim, esta problemática necessita de informação e formação, sendo importante compreender o acolhimento, para que haja um bom acompanhamento do paciente, necessitando que o mesmo seja bem executado desde a porta de entrada e por todos os profissionais.

Por tanto, a necessidade do acolhimento aos usuários com problemas decorrentes do uso, abuso ou dependência do crack, álcool e outras drogas, torna-se relevante por conta da visão negativa destes, sendo necessário desmistificar tal percepção não só na sociedade, mas na equipe de saúde que os assiste.

Nesta perspectiva e em consonância com a Política Nacional de Humanização e a sua diretriz do acolhimento, como graduanda em enfermagem, acentuo a importância de compreender a percepção do acolhimento realizado pela equipe do CAPS ad, na visão dos usuários de álcool. Surgindo com isto, o seguinte questionamento: Qual a percepção dos usuários do CAPS ad, do município de Feira de Santana, acerca do acolhimento realizado pela equipe?

Assim, este estudo teve como objetivo descrever a percepção dos usuários do CAPS ad, do município de Feira de Santana - BA, acerca do acolhimento realizado pela equipe. 


\section{METODOLOGIA}

Trata-se de uma pesquisa qualitativa, pois seu objeto não pode ser quantificado, trabalhando com significados, motivos, aspirações, crenças, valores e atitudes (MINAYO, 1999). É de natureza exploratória, pois busca uma abordagem do fenômeno pelo levantamento de informações que poderão levar o pesquisador a conhecer mais a seu respeito e de caráter descritivo (TRIVIÑOS, 2008; GIL, 2010).

A pesquisa foi realizada no Centro de Atenção Psicossocial para usuários de álcool e outras drogas (CAPS ad) do município de Feira de Santana, BA.

Participaram da pesquisa, usuários que apresentavam transtornos decorrentes do uso, abuso ou dependência de álcool e outras drogas, do CAPS ad, do município de Feira de Santana - BA.

No que se refere aos aspectos éticos, foram adotadas as recomendações do que dispõe a Resolução n. 466 de 12 de dezembro de 2012, do Conselho Nacional de Saúde, que trata das diretrizes e normas regulamentares de pesquisas envolvendo seres humanos (BRASIL, 2012).

Para preservação da identidade dos participantes da pesquisa, as falas dos usuários foram identificadas por letras do alfabeto.

Como técnica de coleta de dados, foi utilizada, o Grupo Focal que conforme Lopes e colaboradores (2009) difere-se de outras técnicas principalmente pelo processo de interação grupal, em que a fala trabalhada não é simplesmente descritiva ou expositiva, e sim uma fala em debate.

Assim, foi realizado o grupo focal com os usuários do CAPS ad, tendo como temática o acolhimento, de modo que proporcionou a apreensão dos sentidos e significados, mediante a interação grupal.

Foram realizadas três sessões de Grupo Focal, que ocorreram no próprio CAPS ad, no horário usual do grupo estudado, no período de maio a junho de 2017, com a participação de 11 usuários.

Os dados foram analisados através da Análise de Conteúdo Temática proposto por Minayo (1999), que refere-se à descoberta do que está por trás dos conteúdos manifestos, indo além das aparências do que está sendo comunicado, sendo então encontrado três categorias de análise: Percepção do acolhimento; Satisfação com o acolhimento; e Melhoria no serviço.

\section{RESULTADOS E DISCUSSÃO}

O grupo foi composto por 11 usuários, do sexo masculino, com faixa etária compreendida entre 26 e 49 anos, sendo que a média de vinculação e frequência no CAPS variou de 07 anos a um dia.

Compreendendo que a percepção, a satisfação e a melhoria estão diretamente ligadas ao acolhimento no serviço prestado, a partir dos dados coletados, as respostas dos participantes foram categorizadas em: Percepção do acolhimento; Satisfação com o acolhimento; e Melhoria no serviço.

\section{Percepção do acolhimento}

A categoria percepção do acolhimento nos possibilitou perceber que os usuários possuem uma visão de acolhimento relacionada aos profissionais e a maneira como os tratam, e que o acolhimento parte de toda a equipe do CAPS ad, conforme os relatos:

"[...]desde do início do meu tratamento eu fui bem acolhido por todas as pessoas, desde da, da pessoa que faz a faxina até as assistentes sociais, as enfermeiras, todas as pessoas aqui me tratam super bem[...]" (Usuário A)

"O médico é mais retraído, é tudo de boa ai. A enfermeira também é gente boa. [...]Até o rapaz lá, do portão lá, é gente boa. A moça da, que fica varrendo também é gente boa."(Usuário B)

A percepção de acolhimento dos usuários advém da forma como são tratados durante todo seu tempo de permanência e não somente no primeiro momento de atendimento no 
CAPS ad. Segundo Andrade (2015) o acolhimento é concretizado através de atitudes demonstradas nas relações intersubjetivas diariamente estabelecidas entre os usuários e os profissionais do serviço. Desta forma, as falas dos usuários nos possibilitou apreender que acolhimento não é sinônimo de primeiro atendimento e sim trazem uma concepção ampliada sobre o mesmo, descrevendo-o como a atenção prestada por toda a equipe da instituição, desde a sua porta de entrada.

\section{Satisfação com o acolhimento}

Ao analisarmos a satisfação com a forma com que são acolhidos no CAPS ad, os usuários referiram a boa assistência e o bom atendimento associando-os diretamente com o tratamento recebido, como podemos perceber nas falas:

"[...] eles são profissionais com bastante educação, que não tem preconceito com a gente[...], trata a gente de igual pra igual, mesmo a gente sendo dependente químico." (Usuário A)

"... eu vou falar que eu tenho 07 anos aqui né, sou bem atendido. [...]Esse tempo que tenho aqui só tenho a acrescentar em minha vida." (Usuário D)

Nas falas, os usuários explicitam a contemplabilidade, a confiança e a realização com o acolhimento e como este propicia o vínculo, a construção diária e a adesão ao trtamento.

A Política Nacional de Humanização-PNH (BRASIL, 2013), traz que acolhimento é construído de forma coletiva e que tem como objetivo a construção de relações de confiança, compromisso e vínculo entre o serviço e os usuários. Carvalho (2015, p.40) descreve que "satisfação é uma palavra que expressa o contentamento de um indivíduo com uma situação, serviço ou até mesmo com outros indivíduos e que uma pessoa é satisfeita quando sua expectativa é alcançada." Diante disso o achado traz satisfação como um agente para vinculação dos usuários no serviço.

\section{Melhoria no serviço}

$\mathrm{Na}$ categoria melhoria no serviço, na perspectiva do acolhimento, embora alguns usuários tenham referido que não há necessidade de mudanças, que o serviço prestado é satisfatório e que para os usuários o serviço contempla todas as demandas como referem abaixo:

\section{"Rapaz, ta bom. Não tem nada pra melhorar não." (Usuário C) \\ "Nada, ta bem. Do jeito que ta ta bem." (Usuário E)}

No entanto, alguns usuários trouxeram algumas sugestões para serem incluídas no serviço, como a ampliação de atividades terapêuticas para o grupo estudado, e a atenção prestada às famílias.

"Eu achava que precisava assim ter mais uma terapia, assim, a mais nuns outros dias que atraísse mais a gente né. [...] Assim, fora só essa terapia, tem outras coisas mais pra fazer a gente né, só não ter o grupo aqui, só segunda feira né." (Usuário A)

"É... De melhorar eu acho que, ta ok. O que ta precisando mais assim, é da parte dos profissionais pra família [...] a minha família ela não é preparada, né. [...] Porque não adianta a gente ser ajudado aqui e lá dentro, dentro da nossa casa, é, a nossa mãe não ter como nos ajudar né." (Usuário F)

Tais achados covergem com os estudos de Fonseca (2014) e Zanatta (2012) que reiteram a necessidade da diversificação e aumento de atividades, possibilitando que o serviço seja atrativo para os usuários possibilitando a vinculação com o serviço, visto que, os mesmos relatam melhoria em suas vidas por meio do direcionamento e apoio prestado pelo CAPS ad. Fonseca (2014), Lima (2015) e Zanatta (2012) em seus estudos acerca da percepção dos usuários sobre os serviços substitutivos, também identificaram a satisfação ao serviço prestado e a importância do bom acolhimento desde a chegada do usuário e da relação usuário 
profissional, esta última compreendida como primordial para a atenção psicossocial e a vinculação com o serviço.

\section{CONSIDERAÇÕES FINAIS}

O estudo nos possibilitou apreender a percepção do acolhimento realizado pela equipe do CAPS ad, através do olhar dos usuários, trazendo como achado resultados positivos e satisfatórios sobre o acolhimento na instituição estudada, e nos possibilitando perceber que para os usuários a percepção do acolhimento engloba todos que trabalham na instituição, e que acolhimento não está relacionado somente ao primeiro atendimento, mas sim em todas as instâncias do tratamento. A relação criada entre os usuários e os profissionais e a maneira com que são atendidos faz com que eles se sintam satisfeitos com o acolhimento realizado, o que contribui para a adesão ao tratamento. Assim, este estudo, enquanto graduanda de enfermagem foi de extrema relevância, visto que, para a enfermagem, em que o processo de cuidar é a base da profissão, as informações acerca da percepção do acolhimento pelos usuários, contribui com que as práticas de cuidado se aprimorem, se humanizem e sejam vistas pela sociedade com outro olhar.

\section{REFERÊNCIAS}

ANDRADE, Andréa B. de; BOSI, Maria L. M. Qualidade do cuidado em dois centros de atenção psicossocial sob o olhar de usuários. Saude soc. [online]. 2015, vol.24, n.3, pp.887900.

BRASIL. Ministério da Saúde. Secretaria de Atenção à Saúde. Departamento de Ações Programáticas Estratégicas. Saúde mental no SUS: os centros de atenção psicossocial. Brasília, 2004.

BRASIL. MINISTÉRIO DA SAÚDE. Acolhimento nas práticas de produção de saúde. 2 ed. Brasília: Ministério da Saúde, 2006.

BRASIL. MINISTÉRIO DA SAÚDE. Secretaria de Atenção à Saúde. Política Nacional de Humanização- PNH. Brasília,DF. 2013.

CARVALHO, Amanda P. de; PEDROSA, Evelyne N. Satisfação dos usuários com o acolhimento implantado em uma unidade de saúde da família. Revista Enfermagem Digital Cuidado e Promoção da Saúde. 2015Janeiro/Junho 1(1): 37 - 42

DICIONÁRIO AURÉLIO- Publicado em: 2016-09-24, revisado em: 2017-02-27. Disponível em: 〈https://dicionariodoaurelio.com/acolhimento〉. Acesso em: 09 Mar. 2017

FONSECA, Rayde L. etal.Percepção dos usuários de crack em relação ao uso e tratamento em um Centro de Atenção Psicossocial, álcool e outras drogas. Rev. APS. 2014 abr/jun; 17(2): 214 - 222.

GIL, A. C. Como elaborar projetos de pesquisa. 5. ed. São Paulo:ATLAS S.A, 2010 LIMA, Maria Zilmaet al. Percepção do cuidado em saúde no CAPSad: uma visão do paciente. Saúde (Santa Maria). 2015, Vol. 41, n. 1, Jan./Jul, p.239-248.

LOPES, M. G. K. et al. Grupos focais: uma estratégia para a pesquisa em saúde. Rev SulBras Odontol., 2009.

MERHY, Emerson Elias. A rede básica como construção da saúde pública e seus dilemas. In: Merhy, Emerson Elias; Onocko, Rosana (Org.). Agir em saúde: um desafio para o público. São Paulo: Hucitec. p.71-112. 1997

MINAYO, M. C. S. Pesquisa social: teoria, método e criatividade. 14. ed. Petrópolis, RJ: VOZES, 1999.

SILVEIRA, Pollyanna Santos da et al. Revisão sistemática da literatura sobre estigma social e alcoolismo. Estud. psicol. (Natal) [online]. 2011, vol.16, n.2, pp.131-138. TRIVINÕS, A. N. S. Introdução à pesquisa em ciências sociais: a pesquisa qualitativa em educação: o positivismo, a fenomenologia, o marxismo. São Paulo: Atlas, 2008. ZANATTA, Aline Bedinet al. O centro de atenção psicossocial álcool e drogas sob a percepção do usuário. Revista Baiana de Saúde Pública. 2012 v.36, n.1, jan/mar p.225-237. 